\title{
The fuzzy approach for estimating the creditworthiness and credit risk of issuers of corporate bonds
}

\author{
Simona Hašková ${ }^{1, *}$ \\ ${ }^{1}$ The Institute of Technology and Business in České Budějovice, School of Expertness and Valuation, \\ Okružní 517/10, 37001 České Budějovice, Czech Republic
}

\begin{abstract}
The uncertainty in the financial market is often perceived as a risk of deviation from expected results. However, uncertainty is associated with vagueness in the sense of ambiguity or obscurity, which, unlike the risk, is not describable in the form of deterministic or stochastic models. Given the vagueness of the data entering the credit risk assessment models, the fuzzy decision-making process is introduced in the theoretical part and implemented in the application part as an effective alternative to standard models. The fuzzy approach is used to address the problem of the creditworthiness of the corporate bonds issuers and the credit risk. Data sources are of a qualitative and quantitative nature based on the ratings of Standard and Poor's and Moody's and financial indicators relevant for the creditor. The resulting creditworthiness and credit risk values rectify the credit ratings of rating agencies and are the original contribution to the topic solved. In conclusion, the impact of company ownership on the creditor's subjective perception of creditworthiness, or respectively credit risk is outlined.
\end{abstract}

Key words: fuzziness, creditworthiness, credit risk, ROA, rating

\section{Introduction}

A typical feature of the financial market is uncertainty. This uncertainty is standardly conceived in terms of risk and described by probabilistic and statistical models. However, there is often vagueness in terms of inaccuracy, ambiguity, obscurity behind uncertainty, which, unlike uncertainty understood as risk, is not describable in the form of deterministic or stochastic models on which an objective prediction can be established. In financial practice, however, it is often silently assumed that the uncertainty in the sense of vagueness, regardless of its nature, can be considered a random phenomenon that can be handled, for example, by a distribution function.

For the purpose of credit risk analysis the structural models are used which, as known, overestimate corporate bonds. Structural models use the contingent claims approach to evaluate the put options in the agreement between creditors and equity holders. In practice, these models are applied despite their unsatisfactory explanation of corporate bonds current prices and spreads ([1]).

\footnotetext{
*Corresponding author: haskovas@post.cz
} 
The reduced models based on rating evaluation belong to other frequently used instruments for credit risk assessment. These models lean on the assumption that bonds grouped according to the rating values are homogeneous in terms of risk. For each risk, group estimates of several characteristics are made such as the spot yield curve, the probability of default and the rate of return. These estimates are then used to calculate the theoretical price of each bond in the group. In addition to selected financial indicators and other information, whose exact set is not known, credit rating agencies derive their ratings, to a certain extent, from subjective factors and variables that are not directly related to a particular firm. Additionally, the method used to allocate the output estimates based on input variables is unknown. A practical consideration of credit rating is the credit spread, i.e. the credit spread between the corporate debt and the benchmark level, such as government bonds, of corresponding yield curve.

Elton et al. in [2] identified bond and rating characteristics beyond the rating categories of S \& P and Moody's, which provide important information for the valuation of corporate bonds. These include, for example, the differences between S \& P and Moody's ratings, the rating of the bond and the rating of the company issuing the bond or whether the bond is new or has been traded for more than a year.

The risk of a badly rated bond can mask excessive credit risk, which, in the extreme case, can result in the inability of an issuer company to pay the debts to which it has been committed by issuing the bond. Credit risk is closely related to the company's creditworthiness, which expresses the credibility of an economic entity to repay its debts (see [3]). The highest financial creditworthiness is usually attributed to sovereign bonds due to the state repayment guarantee. On the other hand, some corporate bonds may have a low credit score, the lowest financial creditworthiness is usually linked with junk bonds (more in [4], [5]) - see Tab. 1 matching the risk of debt default and bond quality.

Table 1. Ratings of Standard and Poor's a Moody's and the interpretation

\begin{tabular}{|l|c|c|c|}
\hline Ratings & Interpretation & Grade ratings & Risk rate \\
\hline AAA-Aa & Highest-high quality & Investment & None-low risk \\
\hline A-Baa & $\begin{array}{c}\text { Strong-adequate } \\
\text { payment capacity }\end{array}$ & Investment & Medium risk \\
\hline Ba-C & $\begin{array}{c}\text { Likely to fulfil } \\
\text { obligation-high risk }\end{array}$ & Speculative & High risk \\
\hline
\end{tabular}

Source: Own processing according to [6].

Taking into account the uncertainty of the data entering the standard models for the credit risk assessment, the fuzzy multi-criterial decision approach will be further discussed and applied as an effective alternative tool for reducing inaccurate outputs of deterministic and stochastic models, and as a means of refining official ratings.

In the field of financial market the fuzzy approach is used, for example, for evaluating the real options (see also [7], [8], [9]), the asset current value assessment (e.g. [10]), investment projects evaluation (e.g. [11]). Its use can be found in many management areas such as subcontracting (e.g. [12]), energy planning (e.g. [13]), analysis of human reliability (e.g. [14]), etc.

The article has the following structure: the methodological part is devoted to the basics of the fuzzy approach based on which a model of fuzzy multi-criteria evaluation is constructed. In the application section this model is used to assess the creditworthiness of the selected bond issuers and their credit risk. Unlike many previous works, we do not entirely rely on the rating value itself, which is, by its very nature, a vague characteristic, but we also take into account important factors of economic nature from the creditor point of view. 


\section{Methodological approach}

In the tasks of expert analysis or expert control of vaguely defined systems vague terms are usually presented by linguistic variables and their linguistic values (the so-called terms), where the word "linguistic" is used here in the meaning of, in natural language communicated".

Desirable relationship between combinations of the terms of the input linguistic variables and the output linguistic variable are given by a set of rules. The tool of mathematical solution to this type of tasks is the fuzzy logic on which the fuzzy approach is based (more in [15]). The fuzzy approach purposefully modifies the assumptions and thus the conclusions of the so-called ,principle of extension“ of fuzzy logic. Its individual phases can be briefly summarized as follows (the scheme of this procedure described is illustrated in Fig. 1):

- In the first phase of the fuzzy approach, which is the fuzzification of the numerical vector $x=\left(x_{1}, \ldots, x_{n}\right)$ entering the relation $K$, the vector $x$ selects the inferential rules relevant to its multi-criteria evaluation. These are the rules $\left(\left(\mathrm{A}_{1 \mathrm{i}}, \ldots, \mathrm{A}_{\mathrm{nj}}\right), \mathrm{B}_{\mathrm{k}}\right) \in P$, in which formalizations of terms $\mathrm{A}_{1 \mathrm{i}}, \ldots, \mathrm{A}_{\mathrm{nj}}$ on the left side, all numbers $\mu_{\underline{A}} l i$ $\left(x_{1}\right), \ldots, \mu_{\underline{A} n j}\left(x_{n}\right)$ are nonzero.

- Moving from the symbolic notation $\left(\left(\mathrm{A}_{1 \mathrm{i}}, \ldots, \mathrm{A}_{\mathrm{nj}}\right), \mathrm{B}_{\mathrm{k}}\right)$ of the selected inference rule to its on $x$ dependent logic notation in the form $\left(\min \left\{\mu_{\underline{A} l i}\left(x_{1}\right), \ldots, \mu_{\underline{A} n j}\left(x_{n}\right)\right\}, \mu_{\underline{B} k}\right)=$ $\left(\mu_{\underline{A}^{*}}(x), \mu_{\underline{B} k}\right)$ we obtain a number $\mu_{\underline{A}}^{*}(x)$ indicating not only the degree of truthfulness that the situation characterized by the vector $x$ actually occurred, and therefore the degree of eligibility of the rule selection $\left(\left(A_{1 i}, \ldots, A_{n j}\right), B_{k}\right)$ to its solution, but also the degree of significance of the term $B_{k}$ in the multi-criteria evaluation of vector $x . \mu_{\underline{B} k}: Y \rightarrow\langle 0,1\rangle$ is the standard membership function of the elements $y \in Y$ to the fuzzy set $\underline{B}_{k}$. On the other hand $\mu_{\underline{B} k}{ }^{*}: Y \rightarrow\langle 0,1\rangle$ in the form $\mu_{\underline{B}} k^{*}(\mathrm{y})=\min \left\{\mu_{\underline{A}}^{*}(x), \mu_{\underline{B} k}(y)\right\}$ limits from above the function $\mu_{\underline{B} k}$ with the number $\mu_{\underline{A}}^{*}$ $(x)$.

- The components of the relation $K$ will then be the elements of the set $P x=\left\{\mathrm{B}_{\mathrm{k}}\right.$ : $\left.\exists y:\left(\min \left\{\mu_{\underline{A}^{*}}(x), \mu_{\underline{B} k}(y)\right\}>0\right),\left(\left(\mathrm{A}_{1 \mathrm{i}}, \ldots, \mathrm{A}_{\mathrm{nj}}\right), \mathrm{B}_{\mathrm{k}}\right) \in P, y \in Y\right\}$. These are the partial intermediate results whose aggregation (logical sum) we obtain the formalized term $\underline{B}_{\text {agg }}=\left\{\left(y, \mu_{\text {agg }}(y)\right): y \in Y\right\}$ on $Y$, in which it applies

$\mu_{\text {agg }}(y)=\max \left\{\min \left\{\mu_{\underline{A}^{*}}(x), \mu_{\underline{B} k}(y)\right\}:\left(\left(A_{1 i}, \ldots, A_{n j}\right), B_{k}\right) \in P, y \in Y\right\}$.

- The final phase of the fuzzy approach is defuzzification, in which last step we obtain the output value $y_{x}$ of the alternative $\left(a_{1}, \ldots, a_{c}\right) \in A$ as the mean value of the elements $y \in \underline{B}_{\text {agg }}$ weighted by values $\mu_{\text {agg }}(y)$ of their significance. Therefore

$$
y_{x}=\int y \cdot \mu_{a g g}(y) d y / \int \mu_{a g g}(y) d y
$$

where $\int$ is the symbol of a definite integral over the universe $Y$.

The process of the multi-criteria assessment of creditworthiness and credit risk of corporate bond issuers is illustrated in a solution to the specific task whose input parameters are of qualitative and quantitative nature. 


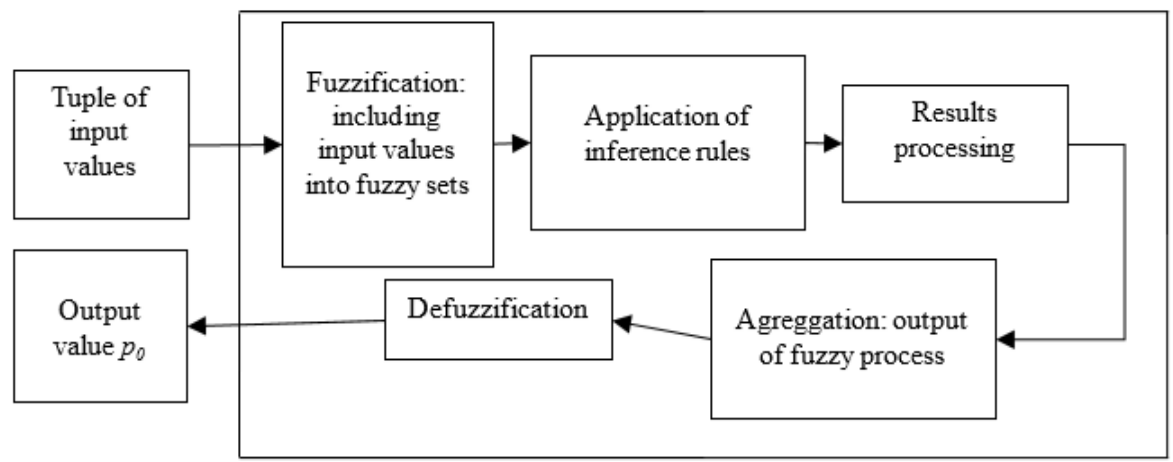

Fig. 1. Schematic representation of the multicriteria problem solving process within the fuzzy approach

Source: Own processing.

\section{Procedures and results of the application of fuzzy approach for evaluating the creditworthiness and credit risk of bond issuers}

Creditworthiness of the bond issuer expresses the credibility of the company in the financial market. It is closely related to the company's economical results, its solvency, the ability and willingness to meet its obligations and ability to valorise the capital invested. In this context, it includes information on, for example, the company's payment discipline, the current status of commitments towards different creditors and the financial situation. In a wider context, it also relates to the company's stability in the market, the reputation or the life cycle of the company. Creditworthiness is often mistakenly identified with the rating the ability to repay debts, which is one of the components of creditworthiness.

In the following analysis of creditworthiness and credit risk, three characteristics are selected, which co-determine the company creditworthiness - the Standard and Poor's and Moody's ratings, the firm production power and the equity to total asset ratio. Credit risk is given as the reciprocal value of creditworthiness [16].

\subsection{Input parameters of the fuzzy model}

The index values of components of the issuer bond quality, which are the official 2017 Rating assessment (R), the Production power (ROA) and the Equity to asset ratio (VA), are input parameters to the fuzzy multi-criteria model to assess the creditworthiness and credit risk of bonds issuers ČEZ, a.s., Letiště Praha, a.s. and Česká telekomunikační infrastruktura a.s. (see Table 1).

Rating assessment (R) is the resultant of ratings of Standard and Poor's and Moody's; it expresses the credibility of the debtor in terms of solvency. As mentioned in the introductory section, index construction includes qualitative and quantitative inputs. The resulting values gain linguistic forms (see Table 1).

Index Production power (ROA) given by the ratio of EBIT to total assets is an indicator of the company's production ability. It is given by the ROA average of the three consecutive past periods in relative terms in the interval $0-0.5$; the higher the ROA value is the higher the production power. It is obvious that ROA is lower in the case of companies with a high proportion of assets, which is the case of all companies analysed. Compared to the average ROA within the industry in 2016, ČEZ, a.s. and Česká telekomunikační 
infrastruktura, a.s. are slightly below average, Letiště Praha, a.s., on the contrary, shows an highly above average result.

The Equity to asset ratio is based on the financial statements of three consecutive past periods, of which the average is calculated. The index is expressed in relative terms in the interval $0-0.8$, with a higher value representing a better result from the creditor point of view. Compared to the 2016 industry average, ČEZ, a.s reaches below average value, Letiště Praha, a.s. above-average value and Česká telekomunikační infrastruktura, a.s. corresponds to the industry average.

Table 2. The input parameters of indexes Rating assessment, Production power and Equity / Asset ratio

\begin{tabular}{|c|c|c|c|}
\hline Comnny/Index & Rating assessment & $\begin{array}{c}\text { Production power } \\
(\mathrm{ROA})\langle 0,0.5\rangle\end{array}$ & $\begin{array}{c}\text { Equity / Asset ratio } \\
\text { (VA) }\langle\mathbf{0 , 0 . 8}\rangle \\
\end{array}$ \\
\hline Companyн & & $\begin{array}{c}\text { Sector Average } \\
2016\langle 0,0.5\rangle\end{array}$ & $\begin{array}{c}\text { Sector Average } \\
2016\langle 0,1\rangle\end{array}$ \\
\hline ČEZ, a.s. (X) & $\begin{array}{c}\text { Low to medium risk } \\
\text { A-, Baal }\end{array}$ & $\frac{0.043}{0.0597}$ & $\frac{0.42}{0.70}$ \\
\hline Letiště Praha, a.s. (Y) & $\begin{array}{l}\text { Low } \\
\text { A1 }\end{array}$ & $\underline{0.29}$ & $\underline{0.8}$ \\
\hline $\begin{array}{l}\text { Česká telekomunikační } \\
\text { infrastruktura, a. s. (Z) }\end{array}$ & $\begin{array}{l}\text { Medium } \\
\text { Baa2 }\end{array}$ & $\underline{0.047}$ & $\frac{0.47}{0.43}$ \\
\hline
\end{tabular}

Source: Justice.cz, Veřejný rejstř́k (2018) [on-line] https://portal.justice.cz/Justice2/Uvod/uvod.aspx, MPO, Finanční analýza podnikové sféry za rok 2016, (2017) [on-line] https://www.mpo.cz/cz/rozcestnik/analyticke-materialy-a-statistiky/analyticke-materialy/financnianalyza-podnikove-sfery-za-rok-2016--228985/ (Own processing).

As noted, there is a direct relationship between the values of these indices, the bonds issuers and the credit risk, which is defined as the reciprocal value of creditworthiness. This provides us with the possibility to solve the assigned task in two steps: the first step is to estimate the creditworthiness of the bond issuer; the second step is to utilize this estimate for the inclusion of the company in the relevant credit risk category.

\subsection{Fuzzy model of the task}

The ROA and VA indices are assigned with numerical data in the interval $\langle 0,0.5\rangle$ and $\langle 0,0.8\rangle$. Index $\mathrm{R}$ is of a qualitative nature. In the set of monitored companies, it is the most favourable for Letiště Praha, a.s., less favourable for ČEZ, a.s. and the least favourable for Česká telekomunikační infrastruktura, a.s.

At first glance, the elements of a given set of companies are separated into classes (categories) defined by a trio of classifiers (individual indices). The non-standard character of the task is that both the class and the classifier function are defined vaguely in the case of the Rating assessment. Therefore, the task as a whole is solved within the fuzzy approach here introduced.

For this purpose, we first normalize the values of inputs by specifying them in $\%$ within the range of their universe. If the universe $U$ of ROA variables is the interval 0 to 0.5 , then $\mathrm{ROA}_{\mathrm{X}}$ is $\approx 8.6 \%, \mathrm{ROA}_{Y} \approx 58 \%$, and $\mathrm{ROA}_{Z} \approx 9.4 \%$. Analogously, for VA values in the $U$ universe within the interval $\langle 0,0.8\rangle$ applies $\mathrm{VAX}_{X}=52 \%, \mathrm{VA}_{Y}=100 \%$ and $\mathrm{VA}_{Z}=58 \%$. The estimate of the values of the R parameter depends on the distribution of points $a$ to $d$ in the definition of the trapezoid fuzzy numbers (see Figure 2) and from it resulting crossover points. If expert opinion, that would help us with the distribution of points $a$ to $d$, is unavailable, it is best to assume that they are distributed evenly, i.e. $a=20 \%, b=40 \%, c=$ $60 \%$ and $d=80 \%$. In addition, it is necessary to normalize $\mathrm{R}$, expressed as the risk of non- 
payment of the obligations, as the rate of solvency of the bond issuer, i.e. as the opposite value of the risk. If the low, low to medium and medium risk is $20 \%, 35 \%$ and $50 \%$ of the maximum risk, i.e. $100 \%$, then $\mathrm{R}_{\mathrm{X}} \approx 65 \%, \mathrm{R}_{\mathrm{Y}} \approx 80 \%$ and $\mathrm{R}_{\mathrm{Z}} \approx 50 \%$ are the solvency rates of the bond issuers. The resulting values of normalized fuzzy inputs are presented in Table 3 .

Table 3. Values of normalized fuzzy inputs in percentage terms

\begin{tabular}{|l|c|c|c|}
\hline Company/Index & $\begin{array}{c}\text { Rating assessment } \\
\text { (R) }\end{array}$ & $\begin{array}{c}\text { Production } \\
\text { power (ROA) }\end{array}$ & $\begin{array}{c}\text { Equity / Asset ratio } \\
\text { (VA) }\end{array}$ \\
\hline ČEZ, a.s. (X) & $65 \%$ & $8.6 \%$ & $52 \%$ \\
\hline Letiště Praha, a.s. (Y) & $80 \%$ & $58 \%$ & $100 \%$ \\
\hline $\begin{array}{l}\text { Česká telekomunikační } \\
\text { infrastruktura, a.s. (Z) }\end{array}$ & $50 \%$ & $9.4 \%$ & $58 \%$ \\
\hline
\end{tabular}

Source: Own processing.

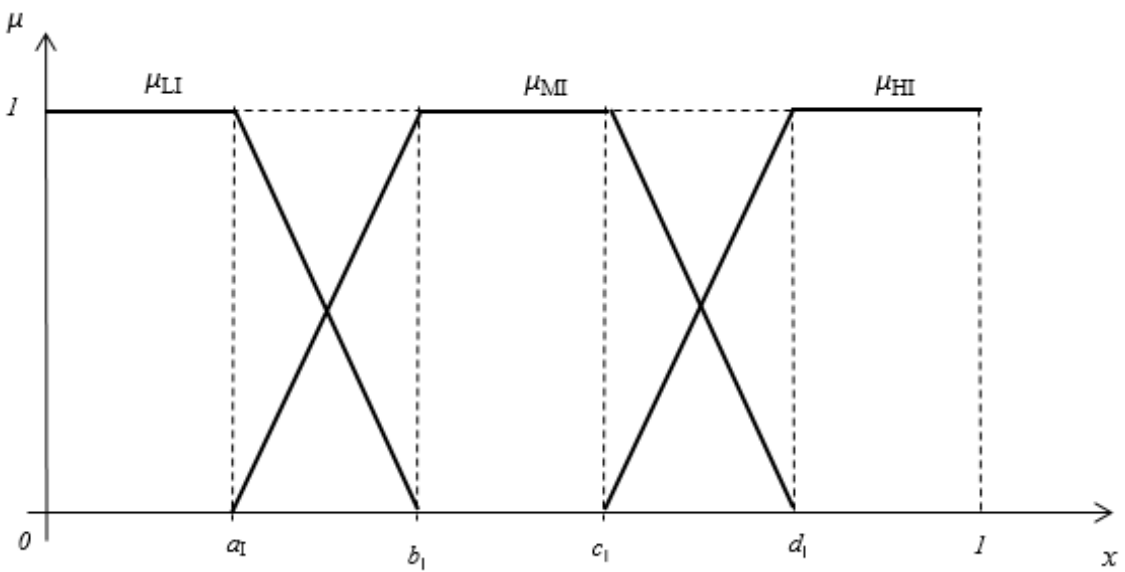

Fig. 2. The course of the membership function $L, M$ and $H$ of linguistic variables R, ROA, VA, and the output function $B$, where $L$ stands for the low, $M$ for the mean and $H$ for the high value of the variable

Source: Own processing.

The following applies:

L) $\quad \mu_{L I}(\mathrm{x})=1$ for $0 \leq \mathrm{x} \leq \mathrm{a}_{\mathrm{I}}$,

$\mu_{L I}(\mathrm{x})=\left(\mathrm{b}_{\mathrm{I}}-\mathrm{x}\right) /\left(\mathrm{b}_{\mathrm{I}}-\mathrm{a}_{\mathrm{I}}\right)$ for $\mathrm{a}_{\mathrm{I}} \leq \mathrm{x} \leq \mathrm{b}_{\mathrm{I}}$,

$\mu_{L I}(\mathrm{x})=0$ for $\mathrm{x} \geq \mathrm{b}_{\mathrm{I}}$

M) $\quad \mu_{M I}(\mathrm{x})=\left(\mathrm{x}-\mathrm{a}_{\mathrm{I}}\right) /\left(\mathrm{b}_{\mathrm{I}}-\mathrm{a}_{\mathrm{I}}\right)$ for $\mathrm{a}_{\mathrm{I}} \leq \mathrm{x} \leq \mathrm{b}_{\mathrm{I}}$,

$\mu_{M I}(\mathrm{x})=1$ for $\mathrm{b}_{\mathrm{I}} \leq \mathrm{x} \leq \mathrm{c}_{\mathrm{I}}$,

$\mu_{M I}(\mathrm{x})=\left(\mathrm{d}_{\mathrm{I}}-\mathrm{x}\right) /\left(\mathrm{d}_{\mathrm{I}}-\mathrm{c}_{\mathrm{I}}\right)$ for $\mathrm{c}_{\mathrm{I}} \leq \mathrm{x} \leq \mathrm{d}_{\mathrm{I}}$,

$\mu_{M I}(\mathrm{x})=0$ otherwise

H) $\quad \mu_{H I}(\mathrm{x})=0$ for $0 \leq \mathrm{x} \leq \mathrm{c}_{\mathrm{I}}$,

$\mu_{H I}(\mathrm{x})=\left(\mathrm{x}-\mathrm{c}_{\mathrm{I}}\right) /\left(\mathrm{d}_{\mathrm{I}}-\mathrm{c}_{\mathrm{I}}\right)$ for $\mathrm{c}_{\mathrm{I}} \leq \mathrm{x} \leq \mathrm{d}_{\mathrm{I}}$,

$\mu_{H I}(\mathrm{x})=1$ for $\mathrm{x} \geq \mathrm{d}_{\mathrm{I}}$ 
The set of inference rules $P=\{((\underline{R O A}, \underline{V A}, \underline{R}), \underline{B}): \underline{R O A}, \underline{V A}, \underline{R}, \underline{B} \in\{\underline{L}, \underline{M}, \underline{H}\}\}$, where $L$, $M$ and $H$ stands for the low, the medium and the high value of the parameter, has a total of 27 elements in which the selection of the right sides (without knowledge of the matter and the expert's help) is carried out by the ,predominant element" method in the left side vector (if neither of them agrees, then $\underline{B}=\underline{M}$ ), see Table 4 .

Table 4. A set of twenty-seven inferential rules

\begin{tabular}{|c|c|c|c|c|c|c|c|c|}
\hline $\mathrm{LLL} \rightarrow \mathrm{L}$ & $\mathrm{LLH} \rightarrow \mathrm{L}$ & $\begin{array}{l}\mathrm{LMH} \rightarrow \\
\mathrm{M}\end{array}$ & $\begin{array}{l}\mathrm{MMM} \rightarrow \\
\mathrm{M}\end{array}$ & $\mathrm{MLL} \rightarrow \mathrm{L}$ & $\begin{array}{l}\mathrm{MHM} \rightarrow \\
\mathrm{M}\end{array}$ & $\begin{array}{l}\mathrm{HHH} \rightarrow \\
\mathrm{H}\end{array}$ & $\mathrm{HLH} \rightarrow \mathrm{H}$ & $\begin{array}{l}\mathrm{HHM} \rightarrow \\
\mathrm{H}\end{array}$ \\
\hline $\begin{array}{l}\mathrm{LLM} \rightarrow \\
\mathrm{L}\end{array}$ & LHL & $\begin{array}{l}\mathrm{LMM} \rightarrow \\
\mathrm{M}\end{array}$ & $\begin{array}{l}\mathrm{MLM} \rightarrow \\
\mathrm{M}\end{array}$ & $\begin{array}{l}\text { MLH } \rightarrow \\
\text { M }\end{array}$ & $\mathrm{MHH} \rightarrow \mathrm{H}$ & $\mathrm{HLL} \rightarrow \mathrm{L}$ & $\begin{array}{l}\mathrm{HMM} \rightarrow \\
\mathrm{M}\end{array}$ & $\begin{array}{l}\mathrm{HLM} \rightarrow \\
\mathrm{M}\end{array}$ \\
\hline $\begin{array}{l}\mathrm{LML} \rightarrow \\
\mathrm{L}\end{array}$ & $\begin{array}{l}\mathrm{LHM} \rightarrow \\
\mathrm{M}\end{array}$ & $\mathrm{LHH} \rightarrow \mathrm{H}$ & $\begin{array}{l}\mathrm{MML} \rightarrow \\
\mathrm{M}\end{array}$ & $\begin{array}{l}\mathrm{MMH} \rightarrow \\
\mathrm{M}\end{array}$ & $\begin{array}{l}\mathrm{MHL} \rightarrow \\
\mathrm{M}\end{array}$ & $\begin{array}{l}\mathrm{HHL} \rightarrow \\
\mathrm{H}\end{array}$ & $\mathrm{HMH} \rightarrow \mathrm{H}$ & $\begin{array}{l}\mathrm{HML} \\
\rightarrow \mathrm{M}\end{array}$ \\
\hline
\end{tabular}

Source: Own processing.

\section{Results and discussion}

For ČEZ, a.s. company we get: $P^{*}=\left\{\left(1, \mu_{\underline{L}}\right),\left(0.75, \mu_{\underline{M}}\right),\left(1, \mu_{\underline{M}}\right),\left(0.25, \mu_{\underline{H}}\right)\right\}, B=\{\min \{1$, $\left.\left.\mu_{\underline{L}}\right\}, \min \left\{0.75, \mu_{\underline{M}}\right\}, \min \left\{1, \mu_{\underline{M}}\right\}, \min \left\{0.25, \mu_{\underline{M}}\right\}\right\}, \mu_{\text {agg }}=\max \left\{\min \left\{0.75, \mu_{\underline{M}}\right\}, \min \{0.25\right.$, $\left.\left.\mu_{\underline{M}}\right\}\right\}$, therefore $\mu_{\mathrm{agg}}(y)=0$ pro $y<20, \mu_{\mathrm{agg}}(y)=(y-20) / 20$ for $20 \leq y<35 ; \mu_{\mathrm{agg}}(y)=0.75$ for $35 \leq y<75 ; \mu_{\mathrm{agg}}(y)=(80-\mathrm{y}) / 20$ for $75 \leq y<80 ; \mu_{\mathrm{agg}}(y)=0$ for $y \geq 80$.

By means of the numerical approximation of the integrals values in the formula for calculating the horizontal coordinate of the centre of gravity position, see Part 2 relation (1), the value $p_{0}$ representing the value of the bond issuer creditworthiness can be estimated as

$$
p_{0}=(0.5 \cdot 20+0.75 \cdot(30+40+50+60+70)+0.5 \cdot 80) /(5 \cdot 0.75+2 \cdot 0.5) \approx 50 \% .
$$

Analogously, for Letiště Praha, a.s. company: $P^{*}=\left\{\left(1, \mu_{\underline{M}}\right),\left(1, \mu_{\underline{H}}\right),\left(1, \mu_{\underline{H}}\right)\right\}, B=$ $\left\{\min \left\{1, \mu_{\underline{M}}\right\}, \min \left\{1, \mu_{\underline{H}}\right\}, \min \left\{1, \mu_{\underline{H}}\right\}\right\}, \mu_{\mathrm{agg}}=\max \left\{\min \left\{1, \mu_{\underline{H}}\right\}\right\}$, therefore $\mu_{\mathrm{agg}}(y)=0$ for $y$ $<60 ; \mu_{\mathrm{agg}}(y)=(y-60) / 20$ for $60 \leq y<80 ; \mu_{\mathrm{agg}}(y)=1$ for $80 \leq y \leq 100$. Then

$$
p_{0}=(90+100) / 2 \approx 95 \% \text {. }
$$

For Česká telekomunikační infrastruktura, a.s. company applies: $P^{*}=\left\{\left(1, \mu_{\underline{L}}\right),\left(1, \mu_{\underline{M}}\right)\right.$, $\left.\left(1, \mu_{\underline{M}}\right)\right\}, B=\left\{\min \left\{1, \mu_{\underline{L}}\right\}, \min \left\{1, \mathrm{M}_{\underline{L}}\right\}, \min \left\{1, \mu_{\underline{M}}\right\}\right\}, \mu_{\mathrm{agg}}=\max \{\min \{1, \underline{M}\}\}$, therefore $\mu_{\mathrm{agg}}(y)=0$ for $y<20 ; \mu_{\mathrm{agg}}(y)=(y-20) / 20$ for $20 \leq y<40 ; \mu_{\mathrm{agg}}(y)=1$ for $40 \leq y<60$; $\mu_{\mathrm{agg}}(y)=(80-y) / 20$ for $60 \leq y<80 ; \mu_{\mathrm{agg}}(y)=0$ for $y \geq 80$. Then

$$
p_{0}=(50+60) / 2 \approx 55 \% .
$$

The creditworthiness results can be within the intervals in Fig. 2 interpreted as follows: $0 \leq \mathrm{x} \leq \mathrm{a}_{\mathrm{I}}$ low; $\mathrm{a}_{\mathrm{I}} \leq \mathrm{x} \leq \mathrm{b}_{\mathrm{I}}$ low to medium; $\mathrm{b}_{\mathrm{I}} \leq \mathrm{x} \leq \mathrm{c}_{\mathrm{I}}$ medium; $\mathrm{c}_{\mathrm{I}} \leq \mathrm{x} \leq \mathrm{d}_{\mathrm{I}}$ medium to high; $\mathrm{x}$ $\geq \mathrm{d}_{\mathrm{I}}$ high. From it follows that a high grade of creditworthiness belongs to Letiště Praha, a. s., the middle grade to the other two companies.

As mentioned in the last paragraph of section 3.1, the second step is to utilize the bond issuer creditworthiness for inclusion of the company in the appropriate credit risk category. There is a direct relationship between bond issuer creditworthiness and credit risk creditworthiness is the reciprocal value of credit risk (the overall results are shown in Table 5).

As a result of this relationship the set of basic values of variables breaks down into credit risk classes analogously in the previous sense: $\frac{1}{100} \leq \mathrm{x}<\frac{1}{\mathrm{~d}_{I}}$ low, $\frac{1}{\mathrm{~d}_{I}} \leq \mathrm{x}<\frac{1}{\mathrm{c}_{I}}$ low to medium, $\frac{1}{\mathrm{c}_{I}} \leq \mathrm{x}<\frac{1}{\mathrm{~b}_{I}}$ medium, $\frac{1}{\mathrm{~b}_{I}} \leq \mathrm{x}<\frac{1}{\mathrm{a}}$ medium to high, $\frac{1}{\mathrm{a}_{I}} \leq \mathrm{x}<\infty$ high. 
Within these intervals Letiště Praha, a.s. shows low credit risk value, the remaining companies medium credit risk value.

Table 5. Input parameters of the fuzzy model and resulting output values of creditworthiness and credit risk

\begin{tabular}{|l|c|c|c|c|c|}
\hline Company/Index & $\begin{array}{c}\text { Rating } \\
\text { assessment } \\
\text { (R) }\end{array}$ & $\begin{array}{c}\text { Production } \\
\text { power } \\
\text { (ROA) }\end{array}$ & $\begin{array}{c}\text { Equity / } \\
\text { Asset ratio } \\
\text { (VA) }\end{array}$ & $\begin{array}{c}\text { Bond issuer } \\
\text { creditworthiness }\end{array}$ & $\begin{array}{c}\text { Credit } \\
\text { risk }\end{array}$ \\
\hline $\begin{array}{l}\text { ČEZ, a.s. } \\
(\mathrm{X})\end{array}$ & $65 \%$ & $8.6 \%$ & $52 \%$ & $\begin{array}{c}50 \% \\
\text { Medium }\end{array}$ & $\begin{array}{c}2.00 \% \\
\text { Medium }\end{array}$ \\
\hline $\begin{array}{l}\text { Letiště Praha, } \\
\text { a.s. (Y) }\end{array}$ & $80 \%$ & $58 \%$ & $100 \%$ & $\begin{array}{c}95 \% \\
\text { High }\end{array}$ & $\begin{array}{c}1.05 \% \\
\text { Low }\end{array}$ \\
\hline $\begin{array}{l}\text { Česká } \\
\text { telekomunikační } \\
\text { infrastruktura a.s. } \\
\text { (Z) }\end{array}$ & $50 \%$ & $9.4 \%$ & $58 \%$ & $\begin{array}{c}55 \% \\
\text { Medium }\end{array}$ & $\begin{array}{c}1.81 \% \\
\text { Medium }\end{array}$ \\
\hline
\end{tabular}

Source: Own processing.

The resulting values of creditworthiness, or respectively credit risk could be corrected upwards or respectively downwards due to the fact that a major shareholder of ČEZ, a.s. company is the state (the $70 \%$ share); similarly, Letiště Praha, a.s. is owned by Český Aeroholding, a.s. company whose only shareholder is the Ministry of Finance of the Czech Republic. This fact, in the eyes of investors, can be a guarantee for the repayment of creditors' claims. In the case of Česká telekomunikační infrastruktura, a.s. company the 100 $\%$ owner is the PPF investment group, which has a stable position on the Czech financial market. This also contributes to the growth of subjective credibility in creditors' mind.

\section{Conclusion}

In view of uncertain input data of vague nature entering the standard credit risk rating models, the fuzzy approach has been introduced to handle this uncertainty. In practice, credit risk is often assessed on the basis of reduced models leaning on rating assessments. In addition to selected financial indicators and other information whose exact set is not known, credit rating agencies base their ratings to a certain extent on subjective factors and variables that are not directly related to a particular creditor firm.

The problem of credit risk is here understood as an analysis of a vaguely defined system whose vague concepts are presented by linguistic variables and their linguistic values, the so-called terms. Desirable relationships between combinations of the terms of the input linguistic together with numerical variables, and the terms of output linguistic and numerical variable are specified by a set of rules. The mathematical tool of this type of a task is the fuzzy logic whose individual phases are shown in the diagram in Fig. 1.

The credit risk is closely related to the company's creditworthiness, which expresses the credibility of the economic entity to repay its debts; the reciprocal value of creditworthiness is credit risk. Input parameters for creditworthiness and credit risk estimate of bond issuers ČEZ, a.s., Letiště Praha, a.s. and Česká telekomunikační infrastruktura, a.s. are the index values of the sub-components of the "quality“ of the bond from the viewpoint of the creditors; they are the rating agencies assessments and relevant financial indicators. 
The resulting values of the creditworthiness and credit risk of bond issuers qualitatively and quantitatively improve the standard ratings of rating agencies. The fuzzy approach can be considered as an appropriate alternative not only to reduced models but also to deterministic and stochastic methods.

\section{References}

1. S. M. Schaefer, I. A. Strebulaev, Structural models of credit risk are useful : Evidence from hedge ratios on corporate bonds. Journal of Financial Economics, 90(1), 1-19, (2008)

2. E. J. Elton, M. J. Gruber, D. Agrawal, C. Mann, Factors affecting the valuation of corporate bonds. Journal of Banking \& Finance, 28(11), 2747-2767, (2004)

3. M. Vochozka, V. Machová, Enterprise Value Generators in the Building Industry. SHS Web of Conferences, EDP Sciences - Innovative Economic Symposium 2017, 39, (2017)

4. V. Stehel, M. Vochozka, The analysis of the Economical Value Added in transport. Naše more: znanstveno-stručni časopis za more i pomorstvo, 63(3 Special Issue), 185188, (2016)

5. K. Ayotte, Bankruptcy and enterpreneurship : The value of a fresh start. The Journal of Law, Economics, \& Organization, 23(1), 161-185, (2006)

6. G. E. Pinches, K. A. Mingo, A multivariate analysiss of industrial bond ratings. The Journal of Finance, 28(1), 1-18, (1973)

7. C. Carlsson, R. Fullér, A fuzzy approach to real option valuation. Fuzzy sets and systems, 139(2), 297-312, (2003)

8. M. Collan, R. Fullér, J. Mezei, A fuzzy pay-off method for real option valuation. Advances in Decision Sciences, 2009, 1-16, (2009)

9. Z. Zmeškal, Application of the fuzzy-stochastic methodology to appraising the firm value as a European call option. European Journal of Operational Research, 135(2), 303-310, (2001)

10. J. S. Yao, M. S. Chen, H. W. Lin, Valuation by using a fuzzy discounted cash flow model. Expert Systems with Applications, 28(2), 209-222, (2005)

11. S. H. Ho, S. H. Liao, A fuzzy real option approach for investment project valuation. Expert Systems with Applications, 38(12), 15296-15302, (2011)

12. W. Ho, X. Xu, P. K. Dey, Muti-criteria decision making approaches for supplier evaluation and selection: A literature review. European Journal of operational research, 202(1), 16-24, (2010)

13. S. D. Pohekar, M. Ramachandran, Application of multi-criteria decision making to sustainable energy planning - A review. Renewable and Sustainable Energy Reviews, 8(4), 365-381, (2004)

14. M. Grabisch, The application of fuzzy integrals in multicriteria desicion making. European Journal of Operational Research, 89(3), 445-456, (1996)

15. S. Hašková, P. Volf, The contribution of foreign direct investments to the convergence of regions in the Czech Republic. Littera Scripta, 2, 23-33, (2017)

16. A.Saunders, L. Allen, Credit risk management in and out of the financial crisis: new approaches to value at risk and other paradigms. 528, John Wiley \& Sons, New Jersey, (2010) 